\section{No transfusion is the best transfusion: a rare case}

\author{
Dibyajyoti Sahoo, ${ }^{1}$ Smita Mahapatra, ${ }^{1}$ \\ Rajeev Kumar Nayak, ${ }^{2}$ \\ Debasish Mishra ${ }^{1}$
}

${ }^{1}$ Department of Transfusion Medicine; and ${ }^{2}$ Department of Clinical

Hematology, SCB Medical College, Cuttack, India

\begin{abstract}
Presence of antibodies against red cell antigens remains a major problem in thalassemia patients. $\beta$-thalassemia major patients do commonly suffer from alloimmunization, which is rarely seen in thalassemia intermedia patients. Association of multiple antibodies and antibody against high frequency blood group antigen further complicates the transfusion therapy. Advance immunohematological tests like adsorption, elution, and phenotyping are necessary along with antibody screening and identification. We present a case about a 25-year male thalassemia intermedia patient, whose blood sample when crossmatched found incompatible with more than 100 units of packed red blood cells. Various tests like direct and indirect antiglobulin (Coombs) tests, 3-cell panel, 4cell panel, 10-, 11-, 16-cell panels, adsorption, elution, minor phenotyping were done to resolve the case. We found multiple alloantibodies with no autoantibody. The present case emphasizes on importance of minor phenotyping before first transfusion in all multitransfused patients, importance of immunohematological tests in resolving blood incompatibility and our experience of dealing high frequency antigen.
\end{abstract}

\section{Introduction}

Thalassemia is a autosomal recessive congenital genetic disorder which affect more than 400,000 newborns per year worldwide. ${ }^{1}$ It has high frequency extending from the Mediterranean basin through the Middle East (Iran), India and Southeast Asia. ${ }^{2}$ In India, the carrier rate of $\beta$-thalassemia varies from $3-17 \% .^{3}$ This disease is treated lifelong with red blood cell (RBC) transfusion ${ }^{4}$ and iron chelation therapy. Development of alloimmunization to minor blood group antigens causes difficulties in treatment. Prevalence of alloimmunization in thalassemia patients has been reported to be $5-30 \%$ in the world, which is mostly contributed by the alloimmunization to minor blood group antigens. ${ }^{5}$ Among Asians, the incidence of red cell alloimmunization, is $22 \% .{ }^{5}$ Development of multiple alloantibodies further complicates the transfusion therapy. Present case is a case of Thalassemia intermedia requiring blood infrequently whose transfusion therapy became complicated due to presence of multiple alloantibodies including antibody against high frequency blood group antigen.

\section{Case Report}

Present case is a 25-year male, known case of $\beta$-thalassemia intermedia presented to the Department of Transfusion Medicine, SCB Medical College, Cuttack (India) for compatible blood for transfusion. Hemoglobin of the patient was $6.1 \mathrm{mg} / \mathrm{dL}$. He was a diagnosed case of Thalassemia intermedia. Blood transfusion requirement were less frequent, first transfusion taken when he was 8 years old. Initial requirement were once a year, further increase to one unit transfusion every 6 to 8 months. In last 17 years he had around 25 blood transfusions. Most of the transfusions were whole blood, non leuco-reduced.

In last several months his blood requirement increased and he required around four blood transfusions. There was ongoing hemolysis; hemoglobin was not increasing with blood transfusion. He had jaundice; total bilirubin was raised to $5.6 \mathrm{mg} / \mathrm{dL}$.

Blood sample was received for grouping and cross matching. Cell grouping showed no agglutination with anti sera A and $\mathrm{B}$. There was $4+$ reaction with anti $\mathrm{D}$. Serum grouping showed agglutination with A, B, O, cells. Blood group determined to be ' $\mathrm{O}$ ' positive. With anti $\mathrm{H}$ there was $4+$ agglutination. This ruled out Bombay blood group. Cross matching performed with many units of ' $\mathrm{O}$ ' positive blood but all showed incompatible at saline phase (immediate spin method), 37 degree Celsius temperature and at AHG Phase. Further immunohematological work up was done with patient blood. Direct antiglobulin test (DAT) showed negative, autocontrol negative and indirect antiglobulin test (IAT) showed positive, $3+$ reaction.

Anti body screening was performed with 3-cell panel, orthodiagnostic column agglutination test showed pan positive. With 11-cell panel also pan positivity noted.

Blood sample was sent to reference lab. The sample was tested with IMMUCOR's 4-cell screen panel, 10-cell panel and 16cell panel. Phenotyping was done for patient's cell. We found that the patient had
Correspondence: Dibyajyoti Sahoo, Department of Transfusion Medicine, SCB Medical College, Cuttack, India.

E-mail: dib.jit@gmail.com

Key words: Alloimmunization; phenotyping; adsorption; elution.

Conflict of interest: the authors declare that they have no conflict of interest.

Received for publication: 19 July 2016. Revision received: 13 January 2017. Accepted for publication: 13 February 2017.

This work is licensed under a Creative Commons Attribution 4.0 License (by-nc 4.0).

CCopyright D. Sahoo et al., 2017

Licensee PAGEPress, Italy

Thalassemia Reports 2017; 7:6174

doi:10.4081/thal.2017.6174

R2R2 (DccEE), Kell negative, ' $M$ ' negative, ' $\mathrm{S}$ ' negative ' $\mathrm{N}$ ' positive, 's' positive, ' $\mathrm{Jk}^{\mathrm{a}}$ negative, $\mathrm{Jk}^{\mathrm{b}}$ positive, fya positive, fyb negative.

Antibody identification was done and found out to be antibody reactive at wide thermal amplitude (37 degree Celsius to 22 degree Celsius) with underlying alloantibody. Adsorption/elution showed underlying alloantibody 'anti-e' detected by PEG adsorption. ' $\mathrm{M}$ ' anti body also detected in the patient plasma. This ' $\mathrm{M}$ ' antibody was clinically significant as it was detected at $37^{\circ}$. Final impression was made that the patient had alloimmunization to multiple antibody.

Patient was advised for R2R2 Blood (eantigen negative i.e., DccEE), $\mathrm{M}$ negative AHG cross matched pack cell under very close observation. Since R2R2 blood group is rare phenotype it was very difficult to get such donor. We screened seven hundred units of to get a ' $\mathrm{O}$ ' positive R2R2 blood unit.

M-antigen negative, R2R2 packed red blood cells of same blood group was chosen for the patient and was transfused. Transfusion was uneventful, and patient improved subsequently.

The same case was referred to us after 3 months again for blood transfusion. He got admitted to the hospital with complains of fever for 5 days. His hemoglobin was 6.5 $\mathrm{g} / \mathrm{dL}$. As patient was a known alloimmunized case so ' $\mathrm{e}$ ' and ' $\mathrm{M}$ ' antigen negative ' $\mathrm{O}$ ' blood unit searched. Unfortunately we didn't found single such unit after searching more than 100 blood units. This may be due to rarity of R2R2 blood. Case was discussed with the treating physician and it was made clear that blood transfusion with above anti- 
gen would cause more harm. Patient managed conservatively with antibiotics, antipyretics, fluid. Patient responded well to supportive therapy and discharged subsequently. After two months during his routine check up he was doing well with hemoglobin $8.4 \mathrm{mg} / \mathrm{dL}$.

Similar episode has happened few weeks ago. Patient's hemoglobin dropped to $5.9 \mathrm{~g} / \mathrm{dL}$ following acute infection. This rare blood group R2R2 could not be availed and transfusion not given. Conservative treatment given and he recovered. During the follow up he was doing well with hemoglobin $8.0 \mathrm{mg} / \mathrm{dL}$.Informed consent was obtained from the patient in the study.

\section{Discussion}

Prevention and treatment support of Thalassemia patient with alloantibody remains a challenge always. Alloimmunization may develop due to the $\mathrm{RBC}$ antigenic difference between the blood donor and the recipient, and immune status of recipient. There can be a variable degree of disparity amongst the donors and the recipient as far as minor blood group antigens are concerned, which are not tested for routine transfusions. Therefore alloimmunization can take place during the transfusion therapy. Due to above risk of alloimmunization, patients receiving multiple transfusions should be typed for clinically important blood group antigens including ABO, Rh, Kell, Kidd and Duffy systems, etc. ${ }^{6}$ Percentage of alloimmunization in thalassemia patient was reported from Taiwan $(37 \%),{ }^{4}$ Arab (30\%). ${ }^{7}$

Situations become more difficult when multiple alloantibodies are associated. Such cases are suspected when a compatible match is not found during cross-matching. These are ideal cases when advance immunohematological test are required like adsorption, elution along with antibody screening and identification. Phenotyping also became essential in most cases. Regular transfusion of extended red cell phenotype matched blood is a very effective regimen for such patients. ${ }^{8}$

The overall frequency of ' $\mathrm{e}$ ' antigen is higher than ' $E$ ' in all population. ${ }^{9,10}$ In English population the frequency of $\mathrm{e}$ is $98 \%$ and $\mathrm{E}$ is $29 \% .{ }^{11}$ Overally ' $\mathrm{e}$ ' antigen is considered as high frequency antigen. R2R2 (DccEE) Blood group incidence is very low in all populations. The R2R2 phenotypes of Indian donors as per Makroo et al. and Garg et al. was found to be $0.8 \%,{ }^{12,13}$ when an antibody developed against these antigen it is very difficult to get a matched blood. Maintenance of rare blood group registry will help to overcome these difficulties.

Antigen negative blood units must be transfused whenever any clinical significant antibody is present in the patient. Here we detected two clinical significant antibodies i.e. Anti ' $\mathrm{e}$ ' and Anti 'M'. Rh extended phenotyping helps to resolve these cases but not a replacement for antigen negative blood.

When antigen negative compatible blood is not available, transfusion to be avoided. Our case has shown no transfusion given was really beneficial to the patient.

Considering cost effectiveness, Minor blood group phenotyping is to be done once a lifetime. It helps always in resolving alloimmunized multi transfused patients. There by it increase transfusion interval, decreases transfusion burden thus saves money, resource and manpower.

\section{Conclusions}

Alloimmunization is not an uncommon problem faced in thalassemia patient and become complicated when associated with multiple alloantibody and antibody against high frequency blood group antigen. Any grouping discrepancy or incompatible cross matching report in these patients should be taken seriously. Blood sample in all these case should be subjected to advance immunohematological tests like phenotyping, elution, and adsorption for alloantibody specificity. Alloimmunization preventive measures like AHG crossmatch blood, leucoreduction, pack cell RBC should be a routine protocol. Compulsory implementation of these protocols will decrease alloimmunization in thalassemic patients and improve their life longevity.

\section{References}

1. Angastiniotis M, Modell B. Global epidemiology of hemoglobin disorders.
Ann N Y Acad Sci 1998;30:251-69.

2. Sadeghian MH, Keramati MR, Badiei $\mathrm{Z}$, et al. Alloimmunization among transfusiondependent thalassemia patients. Asian J Transf Sci 2009;3:95-8.

3. Agarwal S, Gupta A, Gupta UR, et al. Prenatal diagnosis in beta thalassemia: an Indian experience. Fetal Diagn Ther 2003;18:328-32.

4. Wang LY, Liang DC, Liu HC, et al. Alloimmunization among patients with transfusiondependent thalassemia in Taiwan. Transfus Med 2006;16:200-3.

5. Singer ST, Wu V, Mignacca R. Alloimmunization and erythrocyte autoimmunization in transfusion dependent thalassemia patients of predominantly Asian descent. Blood 2000;96:3369-73.

6. Wonke B. Clinical management of $\beta$ thalassemia major. Semin Hematol 2001;38:350-9.

7. Ameen R, A Shemmari S, Al Humood $\mathrm{S}$, et al. RBC alloimmunization and autoimmunization among transfusion dependent Arab thalassemia patients. Transfusion 2003;43:1604-10.

8. Philip J, Jain N. Resolution of alloimmunization and refractory autoimmune hemolytic anemia in a multitransfused betathalassemia major patient. Asian J Transf Sci 2014;8:128-30.

9. Mourant AE, Kopec AC, Domaniewska-Sobczak K. The distribution of the human blood groups and other polymorphisms, 2nd edn. London: Oxford University Press; 1976

10. Green FA. Studies of the Rh(D) antigen. Vox Sang 1965;10:32-53.

11. Tills D, Kopec AC, Tills RE. The Distribution of the human blood groups and other polymorphisms. Oxford: Oxford University Press; 1983.

12. Makroo RN, Bhatia A, Gupta R, Phillip J. Prevalence of Rh, Kell, Kidd \& MNS blood group antigens in the Indian blood donor population. Indian J Med Res 2013;521-6.

13. Garg N, Singh DK, Tomar R, Singh B. Phenotype prevalence of blood group systems (ABO, Rh, Kell) in voluntary, healthy donors-experience of a tertiary care hospital in Delhi, North India. J Blood Disord Transf 2015;6:297. 